\title{
EFEKTIVITAS MENGUNYAH BUAH BENGKUANG TERHADAP PENURUNAN DEBRIS INDEKS PADA SISWA KELAS III A SD NEGERI 060930 TITI KUNING TAHUN 2014
}

\author{
Sondang \\ Jurusan Keperawatan Gigi Poltekkes Kemenkes Medan
}

\begin{abstract}
Abstrak
Kebersihan gigi dan mulut sangat perlu supaya tidak ada debris yang terbentuk dan menjadi tempat tinggal bakteri pembentuk lubang gigi.Menyikat gigi sebenarnya hanya membersihkan 1/4atau $25 \%$ dari keseluruhan bagian gigi dan mulut.. Gunakan bantuan memakan buah buahan yang berserat dan berair seperti buah bengkuang untuk mengurangi sisa makanan yang menempel dipermukaa gigi karna apabila sisa makanan ( debris ) mengeras akan menjadi karang gigi yang melekat pada permukaan gigi, terutama pada permukaan kasar dan tidak rata. Untuk mengetahui efektivitas mengunyah buah bengkuang terhadap penurunan debris indeks pada siswa kelas III A SD NEGERI 060930 tahun 2007. Populasi terdiri dari 32 siswa yang diambil dari seluruh siswa kelas III A untuk dijadikan sampel. Untuk memeriksa debriks indeks dipakai alat bantu kaca mulut,sonde,pinset,buah bengkuang,disclosing solution,kapas,cairan desinfektan dan handuk. Dari hasil penelitian diperoleh rata - rata debris indeks sebelum mengunyah buah bengkuang sebesar 1,93dan rata - rata sesudah mengunyah buah bengkuang sebesar 0,69 dimana selisih penurunan debris indeks sebesar 1,24. Dari hasil penelitian yang dilakukan diambil kesimpulan bahwa mengunyah buah bengkuang dapat menurunkan debris indeks.
\end{abstract}

Kata Kunci : Buah Bengkuang,Debris Indeks

\section{PENDAHULUAN}

\section{Latar Belakang}

Menurut UU no 36 tahun 2009 BAB 1 pasal 1 tentang kesehatan, kesehatan adalah keadaan sehat, baik secara fisik, mental, spritual maupun sosial yang memungkinkan setiap orang untuk hidup produktif secara sosial dan ekonomis. Tujuan pembangunan kesehatan menuju Indonesia sehat 2010 mengacu pada Undang Undang R.I No. 36 tahun 2009 tentang kesehatan, adalah Pembangunan kesehatan bertujuan untuk meningkatkan kesadaran, kemauan, dan kemampuan hidup sehat bagi setiap orang agar terwujud derajat kesehatan masyarakat yang setinggi-tingginya, sebagai investasi bagi pembangunan sumber daya manusia yang produktif secara sosial dan ekonomis. (UU no 36 tahun 2009/ tentang kesehatan).

Sehat adalah suatu kondisi di mana segala sesuatu berjalan normal dan bekerja sesuai fungsinya dan sebagaimana mestinya.Kesehatan merupakan bagian terpenting dalam kehidupan yang mencirikan kondisi baik dan sejahtera dalam menjalani kehidupan, keadaan kesehatan seseorang termasuk seperti tubuh sehat, jiwa sehat, dan secara sosial memungkinkan untuk hidup produktif baik secara sosial maupun ekonomi.

Gigi dan mulut merupakan bagian tubuh yang sangat penting. Didalam mulut terdapat terdapat banyak saraf yang berhubungan dengan seluruh bagian tubuh. Disekitar gigi yang yang dilingkari oleh jaringan gusi terdapat saraf- saraf yang berhubungan dengan bagian tubuh kita. (Grace.W.Susanto,2011)

Mulut merupakan pintu gerbang semua makanan dan dan minuman yang masuk ketubuh.makanan apa pun yang masuk kedalam mulut sebagian akan menyangkut atau tertinggal di diantara gigi,gusi,dan lidah. Sisa makanan kemudian membusuk dan memberikan respon peradangan (inflamasi), khususnya pada jaringan lunak (periodontal),atau respon pada gigi yang menyebabkan gigi berlubang.(Grace.W.Susanto,2011)

Maka dari itu gigi dan mulut harus dijaga kebersihannya salah satunya dengan cara menyikat gigi secara teratur. Menyikat gigi yang di anjurkan adalah setiap pagi sehabis makan dan malam sebelum tidur. Untuk menentukan kebersihan gigi dan mulut seseorang dapat diukur dengan menggunakan indeks. Indeks adalah suatu angka yang menunjukan keadaan kebersihan gigi yang di dapat pada waktu melakukan pemeriksaan, dengan cara mengukur luas permukaan gigi yang tertutup oleh debris. Debris adalah sisa makanan yang melekat pada permukaan gigi.

Angka debris indeks dapat di pengaruhi oleh jenis makanan yang di makan seseorang. Jenis makanan ini dapat berupa makanan yang berserat, berair atau makanan manis, lunak dan melekat. Selain faktor makanan debris indeks juga dapat di pengaruhi oleh faktor kebiasaan seperti menyikat gigi sesudah makandan sebelum tidur. Angka debris indeks ini dapat di turunkan dengan cara memakan makanan yang berserat dan berair. 
Buah - buahan merupakan makanan yang memiliki serat dan berbagai macam vitamin. Banyak manfaat yang diperoleh dari buah - buahan secara teratur. Selain bagus untuk kesehatan tubuh juga bagus untuk kesehatan gigi dan mulut. Serat dalam buah - buahan merupakan pembersih alamiah pada permukaan gigi,membantu membersihkan sisa makanan yang menempel pada gigi selama proses mengunyah.

Makanan dan kesehatan mulut yang baik merupakan faktor yang paling penting dalam pencegahan penyakit yang terdapat dalam mulut. Makanan yang berserat adalah makanan yang mempunyai daya pembersih gigi yang baik. Pada saat kita mengunyah makan ini dapat membersihkan gigi dari debris. Makanan yang bersifat seperti ini adalah jenis buah - buahan.(Tarigan,1990 )

Buah Bengkuang merupakan buah yang memiliki kandungan serat dan air yang cukup banyak. Selain itu buah ini juga memerlukan pengunyahan yang cukup keras sehingga dapat mendorong sekresi ludah. Sehingga buah bengkuang dapat membersihkan gigi dari sisa sisa makanan secara alami, jadi dapat mempengaruhi angka debris indeks seseorang. Dalam penelitian ini, peneliti akan membandingkan perbedaan kebersihan gigi sebelum dan sesudah mengunyah buah bengkung.

Berdasarkan uraian data diatas, peneliti akan melakukan penelitian tentang Efektivitas Mengunyah Buah Bengkuang Terhadap PenurunanDebris Indeks. Penelitian ini dilakukan pada siswa kelas III A SD NEGERI 060930 Titi Kuning.

\section{Tujuan}

1.Tujuan Umum

Penelitian ini bertujuan untuk mengetahui Efektivitas Mengunyah Buah Bengkuang Terhadap PenurunanDebris Indekspada Siswa kelas III A SD NEGERI 060930 Titi Kuning.

Sampel adalah sebagian yang diambil dari keseluruhan objek yang di teliti dan dianggap mewakili seluruh populasi (Notoatmodjo, 2010). Bila subjek lebih dari 100 maka sample di ambil antara 10-15\%, atau 20 25\% atau apa bila subyek kurang dari 100 lebih baik di ambil semua sehingga penelitian merupakan penelitian populasi (arikunto, 2002).

Dalam penelitian ini sampel yang di gunakan adalah siswa kelas III A yang berjumlah 32 orang (Total sampling ). Siswa kelas III A lebih mudah untuk diarahkan dan dibimbing dalam melaksanakan survei penelitian.

\section{HASIL PENELITIAN}

\section{Hasil Penelitian}

Penelitian yang berjudul "Efektifitas Mengunyah Buah Bengkuang terhadap Penurunan Debris Indeks pada Siswa kelas III A SD NEGERI 060930 Titi Kuning” telah di laksanakan pada tanggal 16 dan 17 Mei 2014 di SD NEGERI 060930 Titi Kuning. Penelitian ini lakukan pada siswa kelas III A dengan jumlah sampel 32.

1. Debris Indeks Sebelum Mengunyah Buah Bengkuang
Dari Penelitian yang telah di lakukan di dapatkan hasil debris indeks sebelum mengunyah buah bengkuang, sebagai berikut :

Tabel 1. Distribusi Frekuensi Presentase Debris Indeks (DI) sebelum mengunyah buah bengkuang pada siswa kelas III A di SD NEGERI 060930 Titi Kuning.

\begin{tabular}{|c|c|c|c|c|c|c|c|c|c|}
\hline \multirow{3}{*}{ Perlakuan } & \multicolumn{6}{|c|}{ Debris Indeks } & \multirow{3}{*}{$\mathrm{N}$} & \multirow{3}{*}{$\begin{array}{l}\text { Tota } \\
1 \\
\%\end{array}$} & Rat \\
\hline & \multicolumn{2}{|c|}{ Baik } & \multicolumn{2}{|c|}{ Sedang } & \multicolumn{2}{|c|}{ Buruk } & & & \\
\hline & $\mathrm{n}$ & $\%$ & $\mathrm{n}$ & $\%$ & $n$ & $\%$ & & & \\
\hline $\begin{array}{l}\text { Sebelum } \\
\text { Menguny } \\
\text { ah Buah } \\
\text { Bengkua } \\
\text { ng }\end{array}$ & 0 & $\begin{array}{l}0 \\
\%\end{array}$ & $\begin{array}{l}1 \\
2\end{array}$ & $\begin{array}{l}37,5 \\
\%\end{array}$ & $\begin{array}{l}2 \\
0\end{array}$ & $\begin{array}{l}62,5 \\
\%\end{array}$ & $\begin{array}{l}3 \\
2\end{array}$ & $\begin{array}{l}100 \\
\%\end{array}$ & \\
\hline
\end{tabular}

Berdasarkan tabel 1 menunjukkan bahwa kriteria Debris Indeks siswa kelas III A SD NEGERI 060930 Titi Kuning sebelum mengunyah buah bengkuang, sebagian besar adalah buruk dan sebagian kecil ada yang sedang. Untuk Debris Indeks dengan kriteria buruk mengunyah buah bengkuang berjumlah 20 siswa (62,5\%). Sedangkan untuk Debris Indeks dengan kriteria sedang pada mengunyah buah bengkuang berjumlah 12 siswa (37,5\%) dan rara - rata debris indeks sebelum mengunyah buah bengkuang adalah 1,93

\section{Debris Indeks Sesudah Mengunyah Buah Bengkuang}

Dari Penelitian yang telah di lakukan di dapatkan hasil debris indeks sesudah mengunyah buah bengkuang, sebagai berikut :

\begin{tabular}{|c|c|c|c|c|c|c|c|c|}
\hline Tabel 4.2 & & $\begin{array}{l}\text { trib } \\
\text { eks } \\
\text { gkt } \\
\text { GE }\end{array}$ & & & & & & $\begin{array}{c}\text { Debri } \\
\text { bual }\end{array}$ \\
\hline \multirow{3}{*}{ Perlakuan } & \multicolumn{6}{|c|}{ Debris Indeks } & \multirow{3}{*}{$\mathrm{N}$} & $\mathrm{Ra}$ \\
\hline & \multicolumn{2}{|c|}{ Baik } & \multicolumn{2}{|c|}{ Sedang } & \multicolumn{2}{|c|}{ Buruk } & & \\
\hline & $\mathrm{n}$ & $\%$ & $n$ & $\%$ & $n$ & $\%$ & & \\
\hline $\begin{array}{l}\text { Sesudah } \\
\text { Menguny } \\
\text { ah Buah } \\
\text { Bengkuan } \\
\text { g }\end{array}$ & $\begin{array}{l}2 \\
2\end{array}$ & $\begin{array}{l}68, \\
75 \\
\%\end{array}$ & 10 & $\begin{array}{l}31 \\
25 \\
\%\end{array}$ & 0 & $\begin{array}{l}0 \\
\%\end{array}$ & & \begin{tabular}{l|l}
0,6 \\
9 \\
0
\end{tabular} \\
\hline
\end{tabular}

Berdasarkan tabel 2 menunjukkan bahwa kriteria Debris Indeks siswa kelas III A SD NEGERI 060930 Titi Kuning sesudah mengunyah buah bengkuang, sebagian besar adalah baik. Untuk Debris Indeks dengan kriteria baik pada mengunyah buah bengkuang berjumlah 22 siswa (68,75\%) sedangkan kriteria sedang berjumlah 10 siswa ( 31,25\%).Dan tidak ada lagi siswa yang termasuk pada Debris Indeks dengan kriteria buruk. Rata - rata debris indeks sesudah mengunyah buah bengkuang adalah 0,69.

3. Perbedaan Penurunan Debris Indeks Sebelum dan Sesudah Mengunyah Buah Bengkuang

Dari Penelitian yang telah di lakukan di dapatkan hasil perbedaan penurunan debris indeks sebelum dan sesudah mengunyah buah bengkuang, sebagai berikut : 
Tabel 3. Nilai rata - rata dan nilai penurunan DebrisIndeks (DI) sebelum dan sesudah mengunyah buah bengkuang di SD NEGERI 060930 Titi Kuning.

\begin{tabular}{|l|l|l|l|}
\hline \multirow{2}{*}{ Perlakuan } & \multicolumn{2}{|l|}{ Rata Rata Debris Indeks } & \multirow{2}{*}{ Penurunan } \\
\cline { 2 - 3 } & Sebelum & Sesudah & \\
\hline $\begin{array}{l}\text { Mengunyah } \\
\text { buah Apel }\end{array}$ & 1,93 & 0,69 & 1,24 \\
\hline
\end{tabular}

Berdasarkan Tabel 3 menunjukkan bahwa ada perbedaan antara sebelum dan sesudah mengunyah buah bengkuang. Hal Ini dapat dilihat dari rata rata penurunan Debris Indeks setelah mengunyah buah bengkuang adalah 1,24

\section{PEMBAHASAN}

Hasil penelitian menunjukkan bahwa debris indeks siswa kelas III A SD NEGERI 060930 Titi Kuning mengalami penurunan setelah mengunyah buah bengkuang. Penurunan ini terjadi karena makanan berserat dan makanan padat mempunyai kemampuan untuk dapat mendorong sekresi ludah terhadap rongga mulut sehingga terjadi self cleansing di dalam mulut (Milati, 2009). Self cleansing adalah pembersihan secara alami pada gigi terhadap sisa sisa makanan yang tertinggal di dalam mulut (Grandfa, 2007)

Dari hasil penelitian yang telah di lakukan dapat di lihat bahwa debris indeks yang semula termasuk kategori buruk berubah menjadi kategori baik, hal ini terjadi karena makanan padat mempunyai kemampuan untuk dapat mendorong sekresi ludah terhadap rongga mulut sehingga terjadi self cleansing di dalam mulut. Makanan padat selalu mempunyai kandungan serat,dan membutuhkan kerja otot yang lebih untuk menghancurkan makanan. Makanan padat dan juga serat dari buah inilah yang secara fisiologis akan merangsang mulut manusia untuk menghancurkannya sebelum masuk ke saluran pencernaan (Milati, 2009). Sehingga saliva berfungsi sebagai pembersih mulut dari sisa makanan.

Berdasarkan tabel dan gambar 3 dapat di lihat bahwa ada penurunan debris indeks antara sebelum dan setelah mengunyah buah bengkuang, yang artinya mengunyah buah bengkuang efektif dalam menurunkan angka debris indeks, hal ini dapat terjadi karena kandungan air dan kandungan serat pada buah bengkuang sangat banyak, yaitu kandungan serat sebesar 5 gram dan kandungan air sebesar 85,10 gram. Selain itu cara mengunyah dan jumlah kunyah yang di kendalikan dapat mempengaruhi penurunan debris indeks, karena mengunyah akan meningkatkan jumlah air ludah karena pengunyahan dipengaruhi oleh kekerasan dari jenis makanan.

\section{KESIMPULAN DAN SARAN}

\section{Kesimpulan}

Berdasarkan hasil penelitian tentang efektifitas mengunyah buah bengkuah pada siswa kelas III -A di SD NEGERI 060930 Titi Kuning yang telah di lakukan dapat di simpulkan bahwa :
1. Kategori Debris indeks siswa sebelum mengunyah buah bengkuang sebagian besar adalah buruk dan sedang, dengan nilai rata rata 1,93

2. Kategori Debris indeks siswa sesudah mengunyah buah bengkuang sebagian besar adalah baik dan sedang, dengan nilai rata rata 0,69

3. Mengunyah buah bengkuang efektif menurunkan debris indeks karena adanya penurunan dari sebelum mengunyah buah bengkuang dan setelah mengunyah buah bengkuang sebesar 1,24

\section{Saran}

Berdasarkan hasil penelitian yang telah dilakukan maka saran yang dapat peneliti berikan adalah:

1. Diharapkan kepada anak anak sekolah untuk mengkonsumsi buah berserat dan berair sesudah makan maupun untuk keseharian karena buah berserat dapat menurunkan angka debris indeks dan menjaga kebersihan gigi dan mlut.

2. Diharapkan kepada pihak puskesmas dan khususnya tenaga kesehatan gigi untuk memberikan penyuluhan tentang manfaat buah buahan yang berserat dan berair untuk menjaga kesehatan gigi dan mulut

3. Diharapkan kepada orang tua agar mengontrol kesehatan gigi anaknya dengan cara menganjurkan memakan buah buahan yang berserat.

\section{DAFTAR PUSTAKA}

Agam.F.E.2013.Seputar Kesehatan Gigi dan Mulut. Yogyakarta:Andi

Anandita T.P.2010.Menjaga Kebersihan Gigi dan Mulut.Bandung:Quadra.

Arikunto,S.2006.Prosedur Penelitan Suatu Pendekatan Praktek.Jakarta:RinekaCipta

Grandfa. 2007. Efektifitas Mengunyah Buah Apel dan Buah Jambu biji Terhadap Perubahan Angka Debris Indeks pada Siswa Kelas VII SMP N 24 SEMARANG

2010.

Duniasukasuka,blogspot.com/2010/07/karya-tulisilmiah

Herijulianti,E.T Svasti dan S Artini.2002.Pendidikan Kesehatan Gigi. Jakarta:Kedokteran EGC

Machfoedz,I,2005.Menjaga Kesehatan Gigi dan Mulut Anak-Anak dan Ibu Hamil. Yogyakarta: Fitramaya

Milati.2009. Efektifitas Mengunyah Buah Apel dan Buah Jambu biji Terhadap Perubahan Angka Debris Indeks pada Siswa Kelas VII SMP N 24 SEMARANG 2010. Duniasukasuka,blogspot.com/2010/07/karya-tulisilmiah

Mc Devitt,W.E.2002.Anatomi Fungsional dari Sistem Pengunyahan.Jakarta:Kedokteran EGC

Notoatmojo,S.2010.MetodelogiPenelitian Kesehatan.Jakarta:Rineka Cipta 
Susanto,W,Grace.2011.Terapi Gusi Untuk Kesehatan dan Kecantikan.Semarang:Erlangga

Tarigan,asinta.1989.Kesehatan Gigi dan Mulut. Jakarta:Kedokteran EGC

Tarigan, rasnita. 1990.Karies gigi.Jakarta: http://buahbuahku.wordpress.com/2011/03/07/kandunganzat-dan-manfaat-buah-bengkuang/

http://www.dedinewsonline.com/2011/09/manfaat-buahbengkuang.htm 